\title{
Algunas reflexiones acerca del desarrollo de la Justicia Transicional ${ }^{1}$
}

Este comentario, junto a los documentos que analiza, está disponible en www.anuariocdh.uchile.cl

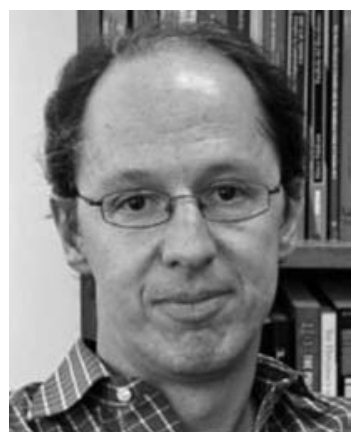

\section{Pablo de Greiff}

Fue Profesor Asociado del Departamento de Filosofía en la Universidad de Nueva York en Buffalo, y Laurance S. Rockefeller Fellow del Centro de Valores Humanos en la Universidad de Princeton. Hoy en día es el Director de Investigaciones de International Center for Transitional Justice en Nueva York. pdegreiff@ictj.org

\section{RESUMEN}

En este breve artículo no pretendo hacer un recuento histórico completo del desarrollo de la justicia transicional durante las últimas tres décadas. Me concentraré en (I) algunos hitos principales del desarrollo del campo y luego en (II) algunos retos pendientes que tienen que ver tanto con las relaciones entre los diferentes elementos de una política de justicia transicional, como con las relaciones entre ésta y otros tipos de intervenciones relevantes a los procesos de transición. (III) Esbozaré una concepción normativa de la justicia transicional y, finalmente, (IV) concluiré con algunas observaciones acerca de cómo ésta contribuye a enfrentar algunos de los retos pendientes.

\section{Los logros de la justicia transicional}

En un momento en el que la justicia transicional, por lo menos entre sus adeptos, parece haberse convertido en algo así como una "herramienta universal" que resuelve una lista aparentemente sin fin de problemas, sin importar el contexto, vale la pena tener en cuenta que este es un campo que nació de la práctica, y por supuesto, con el fin de resolver problemas específicos. El contexto en el cual la práctica se cristalizó fue en realidad el de los países latinoamericanos del Cono Sur. Lo que marcó el inicio del campo no fue tanto la innovación conceptual; después de todo se echó mano de instrumentos en su mayoría familiares. Aun las comisiones de verdad, el instrumento más novedoso en el "saco de herramientas" de la justicia transicional, tenía precedentes amplios en diferentes comisiones de investigación ${ }^{2}$. Por supuesto, la forma específica como los diferentes

1 Los puntos de vista expresados aquí son los del autor y no representan necesariamente la posición del ICTJ. Agradezco a muchos de mis colegas conversaciones que quedan mejor reconocidas en otros de mis artículos a los cuales hago referencia abajo. Conversaciones con Sarah Cliffe me ayudaron a aclarar algunas de las posiciones que adopto aquí. Agradezco a José Zalaquet y a Cecilia Medina la invitación a participar en este número del Anuario y a Claudia Sarmiento por la edición cuidadosa del manuscrito.

2 HAYNER, Priscilla. Unspeakable Truths. New York, Routledge, 2002. 
elementos de la política de justicia transicional vinieron a ser aplicados, y especialmente la relación que llegó a forjarse entre esos elementos, es novedosa y en algunos casos ha resultado exitosa.

Pero hay dos características del contexto en el cual el "paradigma" de la justicia transicional surgió que es importante tener en mente. En primer lugar, las medidas fueron aplicadas en países con grados relativamente altos de institucionalización tanto horizontal como vertical: estos no eran países en los cuales las instituciones del Estado estaban completamente ausentes de porciones grandes del territorio nacional, ni países en los cuales grandes esferas de las relaciones entre los ciudadanos, y especialmente entre estos últimos y las instituciones del Estado, estaban todavía por ser reguladas. Es cierto que esa normatividad resultó insuficiente para evitar los abusos. Pero el punto es que lo que ocurrió fue un quiebre de la institucionalidad y que parte del objetivo de la transición pudo ser entendido en términos de la recuperación de tradiciones e instituciones interrumpidas.

En segundo lugar, las medidas de lo que vino a llamarse justicia transicional se adoptaron como respuesta a un determinado tipo de violaciones, es decir, las asociadas al ejercicio abusivo del poder. Sobra decir que esto revela conexiones profundas entre estos dos factores; sólo Estados relativamente institucionalizados y eficientes pueden cometer violaciones de cierto grado de magnitud, pero, sobre todo, de sistematicidad. En Estados débiles, frágiles, y "fracasados", ocurren abusos de variada índole. Pero la mayor parte de ellos son más el resultado de algo similar al caos social que de la adopción e implementación de políticas abusivas ${ }^{3}$.

El punto principal, en este contexto, es que para quienes apoyaron las medidas de justicia transicional (avant le nom) el tipo de problema al cual éstas pretendían responder era claro: las medidas de justicia transicional fueron propuestas como herramientas para saldar déficits de justicia (en el sentido estrecho de accountability) sin exacerbar problemas de inestabilidad política. Más adelante, cuando regresemos a la identificación de tendencias veremos cómo y por qué esto ha cambiado, y los retos que se generan cuando se intenta implementar las medidas en contextos con características diferentes a las dos señaladas y por tanto también con otros fines.

Antes de ahondar en los retos, sin embargo, comienzo por mencionar algunos logros del campo.

El primer gran logro del campo que es importante poner de relieve es la consolidación del mismo. Que la justicia transicional logró consolidarse en un campo no cabe duda alguna. Tiene todas las características de un campo, incluyendo especialistas, instituciones dedicadas a él, oficinas a cargo del tema en instituciones multilaterales, ministerios, etc., documentos internacionales que versan sobre el tema, cursos universitarios y revistas académicas. Nada de esto podía darse por sentado. Una forma de describir el logro hace patente su magnitud: el campo logró superar -si no en el sentido de resolver todas las diferencias por lo menos en el sentido de mantenerlas bajo control- las "tendencias centrífugas" propias de un campo que intenta integrar diferentes medidas; al contrario del trabajo en derechos humanos clásicamente entendido (es decir, al modo corriente en el período en el que la justicia transicional estaba emergiendo) que promovía básicamente la judicialización de casos de violaciones de derechos humanos, la justicia transicional desde muy temprano intentó adoptar una serie de medidas que fuera de la judicialización incluían también el esclarecimiento de la verdad, la reparación a las víctimas y algunos aspectos de la reforma institucional.

3 Como lo expresó Michael Ignatieff: "el caos ha reemplazado a la tiranía como el nuevo reto para los derechos humanos en el Siglo XXI". Ver IGNATIEFF, Michael. State Failure and Nation Building. En: HOLZGREFE, J. L. y KEOHANE, R. (Eds.). Humanitarian Intervention: Ethical, Legal, and Political Dilemmas. Cambridge, Cambridge University Press, 2003, p. 321 . 
No puedo aquí hacer un recuento detallado del curso que tomó la consolidación de una noción de justicia transicional que integra estos elementos. Esta es la noción que quedó plasmada en el reporte del Secretario General de las Naciones Unidas del 2004, reporte que es buen reflejo de la presencia a nivel internacional que el tema ya había adquirido entonces:

La noción de "justicia de transición" que se examina en el presente informe abarca toda la variedad de procesos y mecanismos asociados con los intentos de una sociedad por resolver los problemas derivados de un pasado de abusos a gran escala, a fin de que los responsables rindan cuentas de sus actos, servir a la justicia y lograr la reconciliación. Tales mecanismos pueden ser judiciales o extrajudiciales y tener distintos niveles de participación internacional (o carecer por completo de ella) así como abarcar el enjuiciamiento de personas, el resarcimiento, la búsqueda de la verdad, la reforma institucional, la investigación de antecedentes, la remoción del cargo o combinaciones de todos ellos ${ }^{4}$.

Pero que hubo "batallas internas" dentro del campo, que nacieron de la necesidad de hacer coherentes estos elementos dispares, no resulta extraño ni desconocido para quienes siguieron los debates "justicia versus verdad" en los primeros años de la década de los noventa ${ }^{5}$. La tensión entre la justicia y la verdad es el ejemplo más claro de algunos de los debates internos del proceso de consolidación del campo, pero no el único. Cualquiera de esas batallas hubiera podido deshacer o prevenir la emergencia de la justicia transicional como un campo integrado. Que el campo haya logrado solidificarse a pesar de esas tensiones es en mi opinión su primer gran logro. Por supuesto, no pretendo afirmar que todas las tensiones están resueltas. Regresaré a este punto más adelante, cuando trate algunos de los retos pendientes.

El segundo gran logro de la justicia transicional, cuya "popularidad" en círculos internacionales, políticos, académicos, activistas, y otros, pone de manifiesto, es haber logrado no sólo su consolidación, sino su "normalización". La justicia transicional, independientemente de las variaciones en la forma de implementación de sus diferentes componentes en diferentes países, se convirtió en parte del paquete de medidas predeciblemente discutidas y frecuentemente adoptadas en situaciones de transición. Esto es cierto tanto en situaciones de transición que gozan (o sufren) de involucramiento internacional obvio, como de aquellas transiciones lideradas esencialmente por actores locales; países como Sudáfrica, Perú o Marruecos, en los cuales los procesos de transición fueron liderados por actores nacionales predominantemente, adoptaron la retórica y la práctica de la justicia transicional tanto como Timor Oriental, por ejemplo, cuya transición ocurrió bajo el mandato de las Naciones Unidas, o Sierra Leona, en donde la comunidad internacional dejó sentir su influencia no sólo mediante la creación de un tribunal híbrido, sino participando activamente en todas las medidas de justicia transicional.

4 Informe del Secretario General "El Estado de derecho y la justicia de transición en las sociedades que sufren o han sufrido conflictos". S/2004/616, August 23, 2004. Hay diferencias importantes con el original, en inglés. El párrafo dice: "The notion of transitional justice discussed in the present report comprises the full range of processes and mechanisms associated with a society"s attempts to come to terms with a legacy of large-scale past abuses, in order to ensure accountability, serve justice and achieve reconciliation. These may include both judicial and non-judicial mechanisms, with differing levels of international involvement (or none at all) and individual prosecutions, reparations, truth-seeking, institutional reform, vetting and dismissals, or a combination thereof". Este proceso continúa. El interés por parte de las Naciones Unidas no mengua; en junio del 2010 la presidencia del Consejo de Seguridad le pidió al Secretario General la actualización del reporte del 2004 (S/PRST/2010/11), proceso que está en curso a la fecha de la escritura de este artículo.

5 Ver e.g., ROTBERG, Robert y THOMPSON, Dennis (Eds.). Truth v. Justice. Princeton, Princeton University Press, 2000. Bronwyn Anne Leebaw da una visión de algunas de las discusiones tempranas, en BRONWYN, Anne Leebaw. The Irreconcilable Goals of Transitional Justice. Human Rights Quarterly. 30: 95-118, 2008. 
De nuevo, no sobra aclarar que al hablar de la "normalización" de la justicia transicional no me refiero ni a la uniformización precisa de programas, ni a un consenso sobre sus bondades (o maldades). En todas las esferas del campo, desde el diseño hasta la implementación sigue habiendo desacuerdos profundos. Más radicalmente, el campo sigue teniendo detractores que incluyen no sólo a quienes verían sus intereses inmediatos afectados por la adopción de tales medidas ${ }^{6}$. Pero el hecho es que puede decirse que los detractores combaten ahora lo que ha adquirido al menos el estatus de presunciones en favor de la implementación de este tipo de medidas, presunciones que a veces no prosperan, pero que aún así, de momento, no pierden su carácter.

Hay dos formas nada despreciables de ver la "normalización" de las medidas de justicia transicional; una consiste en la incorporación de las medidas de justicia transicional en la agenda de las organizaciones tradicionales de derechos humanos. Mucho ha cambiado desde cuando tanto Amnistía Internacional como Human Rights Watch miraban con sospecha los mecanismos de justicia transicional, considerándolos intentos por diluir la justicia entendida en términos de criminalización ${ }^{7}$. Ahora ambas instituciones abogan por la adopción de medidas de este tipo. La segunda, más clara aún, es la incorporación de medidas de justicia transicional en la agenda internacional, y de hecho, su incorporación en la arquitectura de protección de derechos humanos a nivel internacional. La Corte Penal Internacional, los tribunales ad hoc, los híbridos, son sólo las manifestaciones más visibles de esta normalización, pero no las únicas. Documentos internacionales con diferentes grados de vinculación, que cubren diversos temas de la agenda de la justicia transicional, son también reflejo de esta normalización ${ }^{8}$. El papel de los mecanismos regionales de derechos humanos, dentro de los cuales el sistema interamericano ocupa un puesto destacadísimo, también refleja el proceso de incorporación de la agenda de la justicia transicional ${ }^{9}$.

Por supuesto a este nivel de generalidad es fácil (e incorrecto) asumir que la influencia ha tenido lugar sólo en una dirección, es decir, que la justicia transicional (o más precisamente sus "agentes", si tiene sentido, para comenzar, hablar de ellos como si formaran una categoría coherente) ha tenido impacto sobre la agenda de derechos humanos aun a nivel internacional. La historia completa tendrá que incluir, por supuesto, las influencias en el sentido contrario, comenzando por el hecho de que la justicia transicional como la entendemos ahora encuentra su génesis en la lucha por los derechos humanos, que a lo largo del desarrollo del campo la justicia transicional también ha integrado las reacciones de los diferentes agentes de los derechos humanos, y en

6 E.g., ACKERMAN, Bruce. The Future of the Liberal Revolution. New Haven, Yale University Press, 1992, insiste en que los esfuerzos por responder a violaciones pasadas malgastan tanto el alto capital moral de los regímenes transicionales como sus bajas capacidades institucionales; MANDAMI, Mahmood. Reconciliation Without Justice. Southern African Review of Books. Nov/Dec: 3-5, 1996, sostiene que los mecanismos de justicia transicional en Sudáfrica excluyeron los crímenes que más afectaron a la población de ese país.

7 Veáse, por ejemplo, BRODY, Reed. Justice: the First Casualty of Truth?. The Nation. Abril 30, 2001.

8 Asamblea General, Principios y directrices básicos sobre el derecho de las víctimas de violaciones manifiestas de las normas internacionales de derechos humanos y de violaciones graves del derecho internacional humanitario a interponer recursos y obtener reparaciones, A/RES/60/147, 21 de marzo de 2006. Otros documentos internacionales importantes acerca de la justicia transicional incluyen: Comisión de derechos humanos, Conjunto de principios actualizado para la protección y la promoción de los derechos humanos mediante la lucha contra la impunidad, E/CN.4/2005/102/Add.1, 8 de febrero de 2005 y los reportes adjuntos de Diane Orentlicher, Estudio independiente, con inclusión de recomendaciones, Sobre las mejores prácticas, para ayudar a los estados a reforzar su capacidad nacional con miras a combatir todos los aspectos de la impunidad, E/CN.4/2004/88, 27 de febrero de 2004, e Informe de Diane Orentlicher, Experta independiente encargada de actualizar el Conjunto de principios para la lucha contra la impunidad, E/CN.4/2005/102, 18 de febrero de 2005; Comisión de derechos humanos, que tratan diferentes medidas de justicia transicional. El carácter vinculante de estos documentos varía de caso a caso, pero este es un tema que no puedo tratar aquí.

9 La historia del desarrollo de la justicia transicional en América Latina no puede ser contada sin mencionar el papel importantísimo que decisiones tales como Velásquez Rodríguez han jugado. 
últimas, que más allá de las contingencias históricas del desarrollo del campo ${ }^{10}$, a nivel conceptual la justicia transicional y los derechos humanos están estrechamente entrelazados.

Independientemente de los detalles de esta historia, lo menos que puede decirse es que la justicia transicional ha participado en lo que retrospectivamente se verá como una época de expansión de los derechos humanos. Esta expansión tiene diferentes dimensiones: desde los ochentas ciertamente se ha expandido el ámbito de los mecanismos que propenden por el respeto por los derechos humanos a nivel global; "temáticamente" se ha expandido la esfera de los derechos para incorporar más efectivamente algunos derechos de las víctimas tales como los derechos a la verdad y a la reparación; se han creado instituciones de diferente tipo para promover esos derechos, y, en general, se ha intentado poner coto a la impunidad hasta el punto de limitar la posibilidad de amnistiar categorías importantes de crímenes, incluyendo el genocidio, crímenes contra la humanidad y crímenes de guerra ${ }^{11}$. Estos son logros que a su vez afectan la forma como la justicia transicional puede ser (y de hecho es) implementada, lo que constituye sólo uno de los factores que ilustran que el campo, lejos de permanecer estático, también cambia por razones tanto internas como externas.

Me he concentrado en esta sección en los logros del "campo", y en lo que sobra de este artículo seguiré usando el campo como sujeto de esta reflexión. No quiero proseguir, sin embargo, sin aclarar que a la larga el campo no importa tanto como los efectos que tiene, los cuales se supone que hacen referencia a la promoción de la justicia y, más concretamente, a la afirmación de normas, el fortalecimiento de regímenes de derecho, el reconocimiento de las víctimas, el estímulo a la articulación de la sociedad civil, etc. A este punto regresaré en la sección III, luego de mencionar algunos retos, pues debe resultar curioso que a pesar de lo exitoso que ha sido el campo resulta todavía difícil encontrar los términos precisos para describir -para no hablar de explicar-sus logros.

\section{Algunos retos pendientes}

Como siempre, no todo es logro. Es importante ahora mencionar algunos retos. Comienzo por dos externos: es indudable que la etapa de la postguerra, y más aún la etapa que siguió a la guerra fría, ha sido una de gran progreso en el desarrollo de la arquitectura internacional de los derechos humanos ${ }^{12}$, progreso en el cual, como dije anteriormente, la justicia transicional jugó algún papel, y del cual es al mismo tiempo manifestación. Pero no es irracional tener dudas acerca de si se podrá decir lo mismo de las próximas décadas. No es irracional, por ejemplo, sospechar que, para usar una generalización, si las décadas de las cuales nos estamos ocupando aquí, las últimas tres, más o menos, fueron décadas "de juristas", las que estamos viviendo ahora son, tal como pueden ser las venideras, décadas "de los economistas". Hay razones para hablar de un nuevo tipo de "desarrollismo" promovido no sólo por China, indiferente a la dimensión de

10 Sobre los orígenes del campo tampoco hay consenso. Para tres versiones diferentes, véase, e.g., ELSTER, Jon. Closing the Books. Cambridge, Cambridge University Press, 2004; TEITEL, Ruti. Human Rights Genealogy. Fordham Law Review. 66: 301-317, 1997 y de la misma autora Transitional Justice Genealogy. Harvard Human Rights Journal. 16: 69-94, 2003; y ARTHUR, Paige. How "Transitions" Reshaped Human Rights: A Conceptual History of Transitional Justice. Human Rights Quarterly. 31: 321-367, 2009.

11 FREEMAN, Mark. Necessary Evils: Amnesties and the Search for Justice. New York, Cambridge University Press, 2009.

12 Esto no es lo mismo que una etapa de progreso en el grado de respeto a los derechos humanos, sin embargo; después de todo, dos de las fuentes de progreso del sistema internacional, los tribunales internacionales ad hoc para la antigua Yugoslavia y para Ruanda, fueron respuesta a atrocidades sistémicas. 
justicia y de derechos, en la cooperación internacional ${ }^{13}$; irónicamente los avances en materia de justicia a nivel de la estructura internacional permiten cierto tipo de relajación con respecto a estos temas. Si a estos dos factores se les suma una crisis financiera a nivel global, y la ansiedad continuada surgida del terrorismo, no es absurdo tener preocupaciones acerca de la suerte de las intervenciones en materia de justicia y de derechos. El último factor externo que creo conveniente tener en mente es un nuevo tipo de filantropía ("entrepreneurial philanthropy") orientada a los "resultados", que explica en parte por qué la fundación filantrópica más importante en la historia (por lo menos desde el punto de vista de capital), la Fundación Gates, no se ocupa en absoluto de temas de justicia ni de derechos, sino que ha orientado sus esfuerzos a temas relacionados con la educación y salud. Esta orientación a los resultados es ahora compartida por una buena parte de las fundaciones filantrópicas americanas, soporte importante del trabajo en temas de justicia a nivel internacional.

Esta preocupación por la medición de impacto es, de hecho, el segundo reto externo que pienso que el campo de la justicia transicional enfrenta ${ }^{14}$. Lo digo no porque piense que la justicia transicional esté en una posición particularmente desfavorable: todos los campos de intervención, especialmente aquellos que dependen de la cooperación internacional, están sometidos a presiones similares y la justicia transicional no es el único que no ha encontrado todavía una forma estándar de demostrar su impacto ${ }^{15}$. Esto, por supuesto, no exime al campo de la necesidad de responder a esta demanda de forma más efectiva, así sea disputando los términos en los que la exigencia está siendo articulada. Personalmente (a) no creo que la justificación última del trabajo en el área de la justicia en general (lo cual es distinto de la justificación de programas particulares en esta esfera) dependa de análisis de "efectividad"16 y (b) en términos más inmediatos, mientras se encuentra consenso sobre cómo hablar acerca del "impacto" del trabajo en áreas de justicia, la adopción rápida de una orientación a los resultados previsiblemente conduce a la erosión (por lo menos temporal) del apoyo al trabajo en esta esfera. De no lograr enfrentar este reto, no es poco probable que el apoyo del cual el campo ha gozado, se debilite ${ }^{17}$.

Me interesan más, sin embargo, los retos más próximos, de alguna forma "internos" al campo. Mencionaré tres retos relacionados entre sí, todos ellos dimensiones del problema de coherencia

13 Los "objetivos del milenio", para mencionar un ejemplo de un consenso internacional acerca del desarrollo, no sólo omiten mención alguna a temas de justicia, sino que no aluden al hecho de que algunos de los bienes particulares acerca de los cuales tratan (educación, salud, sanidad), ni el bien general bajo el cual estos quedan cobijados (el desarrollo) pueden ser también asunto de derechos. Que esto obedezca a razones estratégicas no cambia este hecho. Para una comparación interesante entre la agenda de derechos humanos y la que subyace a los objetivos del milenio, ver ALSTON, Philip. Ships Passing in the Night: the Current State of the Human Rights and Development Debate Seen Through the Lens of the Millennium Development Goals. Human Rights Quarterly. 27: 755-829, 2005. La lectura de MCCARTHY, Thomas, Race, Empire, and the Idea of Human Development,. New York. Cambridge University Press, 2009, y de algunos de los ensayos incluidos en TRUBEK, David y SANTOS, Álvaro (Eds.). The New Law and Economic Development, A Critical Appraisal. New York, Cambridge University Press, 2006, me estimularon a pensar en el "desarrollismo".

14 Ver, por ejemplo, la edición especial dedicada a este tema del International Journal for Transitional Justice 4(3), 2010.

15 Las evaluaciones de programas tan diversos como los de desmovilización, desarme y reintegración de excombatientes (DDR), o de reforma legal, para mencionar dos áreas relacionadas con la justicia transicional, pero con historias más largas y que tanto individual como colectivamente han recibido apoyo internacional varios órdenes de magnitud superiores al apoyo recibido por la justicia transicional, están repletos de alusiones a las dificultades pertinentes a la medición del impacto de ambos tipos de programas.

16 La razón por la cual pienso que esto es así es que la medición de impacto ya presupone cierta noción de lo que vale la pena medir (para no hablar de implementar); en cuestiones de justicia discusiones acerca de la efectividad juegan un papel subsidiario al de las obligaciones. Pero de nuevo, esto es cierto para la justicia en general, no para programas específicos.

17 Para un tratamiento más sistemático de las dificultades pertinentes a la explicación y evaluación de la justicia transicional ver el número citado del IJTJ, y mis contribuciones a DE GREIFF, Pablo (Ed.). How Things Work: Explaining Transitional Justice Interventions (De próxima publicación). 
tanto interna como externa del campo: en otro contexto hablé de la importancia de asegurar la coherencia no sólo de cada una de las medidas de justicia transicional, sino entre las diferentes medidas $^{18}$; por razones tanto pragmáticas como conceptuales, es importante diseñar e implementar políticas de justicia transicional que hagan patentes los vínculos entre sus diferentes componentes, es decir, la justicia penal, el esclarecimiento, la reparación a las víctimas y las reformas institucionales. Hay un tipo de coherencia aún más extenso, que debe vincular la política de justicia transicional -la cual definitivamente no puede pensarse que agota la agenda de procesos complicados de transición y transformación política, económica y social- con otras intervenciones con las cuales de hecho coexiste, pero que además inevitablemente se solapa. A este punto regresaré más adelante.

En orden inverso de importancia los retos son los siguientes: creo que un campo que apela a una diversidad de instrumentos está siempre en riesgo de fragmentarse. Es decir, las fuerzas centrífugas, que hasta ahora el campo ha logrado mantener bajo balance, pueden salirse de control. En el caso de la justicia transicional esto puede ocurrir además debido al éxito diferencial de esas medidas y a asuntos de "división de labores" no sólo disciplinarios sino de estructuras de financiación y cooperación internacional de las cuales estas medidas son altamente dependientes. Para ilustrar un escenario posible, el trabajo en temas relacionados con la judicialización de casos de violaciones (que sigue siendo parte del ámbito de los promotores de justicia y de derechos humanos, quienes además constituyen el "pool" más grande de participantes en el campo de la justicia transicional), puede fácilmente subsistir independientemente del trabajo en esclarecimiento histórico, que continúa en una posición no crítica pero tenue en términos de apoyo internacional; las comisiones de verdad en principio "le gustan" a la comunidad internacional, pero a ésta le gusta menos financiarlas. Menos dificultades logrando apoyo económico suelen encontrar proyectos de reforma institucional, especialmente aquellos que tienen que ver con la reforma de servicios de seguridad ${ }^{19}$. No obstante, por otro lado, el trabajo en este campo no acaba de ser completamente integrado con el resto de los elementos de la justicia transicional: frecuentemente se alega que ésta es una área "técnica" (¡como si la justicia penal o el diseño de programas masivos de reparación no lo fueran!). Más plausible como explicación es que los interlocutores e interesados tanto como los grupos claves en el trabajo de la reforma del sector de seguridad son bastante diferentes a las partes involucradas en otras áreas del trabajo en justicia transicional. Finalmente, las reparaciones, otra medida que en principio goza de más popularidad que apoyo real, está en riesgo constante de politización o de dejar de ser un instrumento de justicia para convertirse en un programa de desarrollo más ${ }^{20}$.

Mantener, sobre todo en la práctica, los vínculos entre todas estas medidas, no es fácil, ni puede darse por hecho. Especialmente si se considera que dichas medidas no pueden abstraerse de las realidades políticas y económicas propias de su implementación y que incluyen hechos como grados diferentes de apoyo y de oposición a nivel local a cada una de ellas, diferentes grados

18 GREIFF, Pablo. Justice and Reparations. En: GREIFF, Pablo (Ed.). The Handbook of Reparations. New York, Oxford University Press, 2006.

19 Ver e.g., PETERSON, Stina, SAMSET, Ingrid, WANG, Vibeke. Foreign Aid to Transitional Justice: The Cases of Rwanda and Guatemala, 1995-2005. En: AMPOS, K. "et al" (Eds.). Building a Future on Peace and Justice: Studies on Transitional Justice, Peace and Development. Springer-Verlag Berlin Heidelberg, 2009, pp. 439-467.

20 No quiero sugerir que las contribuciones que las reparaciones puedan hacer al desarrollo no deban ser ni exploradas más ni maximizadas. Pero insisto en el punto que he hecho en otros lugares; las reparaciones no son lo mismo que los programas de desarrollo, independientemente de otras conexiones posibles, entre otras razones porque las reparaciones descansan sobre el reconocimiento de la responsabilidad (no necesariamente culpabilidad legal) por violaciones pasadas. Para una discusión más profunda sobre las diferencias, ver el trabajo que hice para la Oficina de la Alta Comisionada de Derechos Humanos, Instrumentos del estado de derecho para sociedades que han salido de un conflicto; Programas de Reparaciones. [en línea] <http://www.ohchr.org/Documents/Publications/ReparationsProgrammesSP.pdf> 
de desarrollo en la legislación tanto nacional como internacional con respecto a estos temas, diferentes grados de capacidad, diferentes instrumentos legislativos y administrativos, cada uno con sus partidarios y opositores, que no necesariamente coinciden con respecto a las diferentes medidas, además diferentes fuentes de financiamiento.

Para hacer frente a este reto las comisiones de verdad, frecuentemente encargadas de hacer recomendaciones con respecto a todas estas medidas, y por lo tanto, responsables de mantener la coherencia entre ellas, no son suficientes: no sólo porque el esclarecimiento en sí no goza de apoyo universal en las sociedades en cuestión, sino porque las comisiones de verdad, en parte por ser cuerpos temporales, suelen ser políticamente débiles o, de hecho, haber cesado sus funciones precisamente cuando más se necesitan en términos de implementación y seguimiento ${ }^{21}$. El récord de implementación de las recomendaciones de las comisiones de verdad es tan ambivalente que el campo difícilmente puede asumir que ya ha solucionado el reto de la coherencia entre las diferentes medidas. Continúa pendiente en cierta medida aun asumiendo la solución a los debates entre justicia y verdad. Mientras que no se le dé respuesta adecuada al reto del diseño y la implementación coordinada de los diferentes programas de justicia transicional, no sólo la efectividad de cada uno de ellos sufrirá. Como se verá más adelante, aun por razones semánticas, la posibilidad de interpretar medidas pragmáticamente débiles en clave de justicia depende de su coordinación, lo que aumentará la tendencia de prácticamente todos los gobiernos que enfrentan transiciones de intentar una suerte de intercambio entre las diferentes medidas, el cual normalmente implica debilitar la judicialización de casos y diluir el esclarecimiento, lo que se "compensa" con el ofrecimiento de reparaciones a las víctimas. En el proceso, se desdibuja por completo la naturaleza del concepto de justicia transicional como respuesta adecuada a la violación masiva de derechos humanos ${ }^{22}$.

Otro reto que surge del hecho de que el campo es uno que está construido sobre la implementación de diferentes medidas, u otra dimensión del reto general de la coherencia, es el de la "secuencia" que debe seguir la implementación de la serie. Es claro que de la implementación completamente independiente de cada una de ellas se desprenden problemas; cada una de las medidas, debe aceptarse, es "débil;" no hay ningún país del mundo que pueda alegar que ha perseguido penalmente a cada uno de los responsables de cometer violaciones a los derechos humanos, y menos aún que los ha castigado en proporción al daño que causaron; o que pueda alegar que sus esfuerzos por esclarecer el pasado han aclarado lo que le sucedió a cada una de las víctimas o han hecho pública cada una de las causas o estructuras que hicieron posibles esos abusos; ningún país del mundo puede reclamar que ha reparado a todas las víctimas, y de nuevo menos aún que lo ha hecho en proporción al daño sufrido por ellas; y por último, no hay ningún país que haya reformado todas las instituciones que hicieron parte o por lo menos permitieron

21 En este sentido, la creación en Chile de la Corporación Nacional de Reparación y Reconciliación (1992-96), encargada de darle seguimiento a las recomendaciones de la Comisión de Verdad y Reconciliación (Abril 1990-Febrero 1991), es un ejemplo que merece más examen del que ha recibido. Ver LIRA, Elizabeth. The Reparations Policy for Human Rights Violations in Chile. En: The Handbook of Reparations.

22 Esta puede ser una tendencia creciente. La adopción en Colombia de la retórica de la justicia transicional, seguida de procesos cuya efectividad, cinco años después de la adopción del marco legal establecido por la ley 975 está todavía en cuestión, es sólo un ejemplo de lo que puede ser el creciente uso instrumental de la justicia transicional. No sería el primero; la adopción en Polonia de una tardía ley de exclusión (vetting) fue ampliamente criticada por tener todas las apariencias de una movida en contra de la oposición. Sobre el caso colombiano, ver UPRIMMY, Rodrigo (Ed.). ¿Justicia Transicional sin Transición? Bogotá, DeJusticia, 2006. Sobre el caso polaco, ver CZARNOTA, Adam. The Politics of the Lustration Law in Poland, 1989-2006. En: MAYER-RIECKH, Alexander y DE GREIFF, Pablo (Eds.). Justice as Prevention. Vetting Public Employees in Transitional Societies. Nueva York, Social Sciences Research Council, 2007 y KILLINGSWORTH, Matt. Lustration after Totalitarianism: Poland's Attempt to Reconcile with its Communist past. Communist and Post-Communist Studies 43: 275-284, 2010. 
que los abusos ocurrieran. Las medidas son en este sentido débiles. Parte del argumento a favor de políticas de justicia transicional "holísticas", comprehensivas, coherentes, descansa sobre una aspiración fundada de que la interrelación entre las diferentes medidas facilite que éstas, a pesar de las debilidades que aquejan a cada una de ellas, adquieran el sentido de medidas de justicia y no sólo de concesiones prudentes, de conveniencia a una realidad turbia y complicada ${ }^{23}$. Hay que admitir, sin embargo, que la norma, y no la excepción, es que lo que llamamos "políticas de justicia transicional" tiene algo de abstracción, que con mayor frecuencia los países implementan medidas de una forma no completamente comprehensiva y no sólo gradual en el sentido de que no se implementan todas simultáneamente, sino que sus diferentes elementos no son concebidos desde el principio como partes de un todo. Hay normalmente un alto grado de improvisación, de adaptación, de acomodo, y aun de oportunismo en la forma como se despliegan a lo largo del tiempo los diferentes componentes de lo que se piensa que es una política comprehensiva de justicia transicional.

Desde sus inicios el campo de la justicia transicional ha enfrentado interrogantes acerca de si hay secuencias más o menos apropiadas en el orden en el que las diferentes medidas que propone han de ser adoptadas. Por supuesto no se trata de encontrar una fórmula rígida que resuelva todos los problemas y que pueda ser aplicada sin tener en cuenta factores contextuales. El campo ha hecho de esta ambigüedad una virtud, alegando, con razón, no sólo que el hecho de incluir varias medidas, sino además que estas pueden ser implementadas de diferentes formas, y en diferente orden dependiendo del contexto, lo hace particularmente flexible y adaptable. Esto es cierto, y sin embargo, en parte por la creciente conciencia acerca de los límites institucionales con los que frecuentemente se topa especialmente en situaciones de conflicto y postconflicto, los cuales hacen imperativa la priorización, queda la duda acerca de si todo lo que puede decirse sobre el tema, no sólo con respecto a la secuencia "interna" (es decir, el orden que debe seguir la implementación de las diferentes medidas de justicia transicional), sino también la "externa" (el orden que deben seguir medidas de justicia y otras, especialmente las pertinentes al desarrollo) está ya dicho ${ }^{24}$. Mi impresión es que la "profesionalización" del campo no lo ha hecho más abierto, sino más cerrado a este tipo de consideraciones y que en esto se asemeja cada vez más al trabajo clásico en derechos humanos (no precisamente el paradigma de la perceptividad política o institucional), lo cual no debe sorprender debido al peso relativo de profesionales de ese campo en el de justicia transicional.

Y esto nos trae al tercer gran reto que el campo enfrenta, probablemente el más difícil de todos, la ampliación progresiva de su agenda. De nuevo, como lo mencioné anteriormente, a veces parece como si la justicia transicional se hubiera convertido en una suerte de herramienta de mil usos capaz de resolver todo tipo de problemas en cualquier tipo de contextos. No me preocupo por intentar compilar una lista de los fines que, se alega, la justicia transicional es capaz de lograr, pues aun un mínimo de familiaridad con el campo es suficiente para reconocer este fenómeno. Me interesa no sólo anotar esta proliferación de fines, sino entenderla. Hay cuatro razones que en mi concepto explican esta situación. En primer lugar todas las intervenciones políticas -y no sólo aquellas en el área de la justicia- pueden ser defendidas apelando a diferentes fines. En

23 Ver, DE GREIFF, Pablo. Theorizing Transitional Justice. En: WILLIAMS, Melissa y NAGY, Rosemary (Eds.). Transitional Justice. Nomos vol. L. New York University Press (De próxima publicación).

24 Sobre este tema, ver DE GREIFF, Pablo. Articulating the Links between Transitional Justice and Development: Justice and Social Integration. En: DE GREIFF, Pablo y DUTHIE, Roger (Eds.). Transitional Justice and Development: Making Connections. New York, Social Science Research Council, 2009, y el trabajo que hice para el Banco Mundial en el curso del Reporte de Desarrollo Mundial 2011, Conflicto, Seguridad y Desarrollo "Transitional Justice, Security and Development", accessible en: http://wdr2011.worldbank.org/sites/default/files/pdfs/WDR\%20Background\%20Paper_de\%20 Greiff.pdf?keepThis=true $\&$ TB_iframe $=$ true $\&$ height $=600 \&$ width $=800$ 
segundo lugar, las intervenciones en el área de la justicia, en particular, probablemente porque según algunos están motivadas por "hacer lo correcto", pareciera como si estuvieran exentas de análisis acerca de cuáles son sus efectos, y por tanto, cuáles son los fines que pueden buscarse mediante su adopción. La indiferencia a la forma como estas medidas funcionan de hecho, incluyendo lo que logran y lo que no, genera indisciplina acerca de los fines defendibles de cada intervención. A esta indisciplina la subyace una confusión entre justificación y explicación que no es recomendable reproducir ${ }^{25}$. En tercer lugar, el hecho de que las comisiones de verdad tengan un mandato amplio, que tengan autorización para investigar un rango variado de temas y para hacer recomendaciones acerca de algunos de ellos, ha alimentado la impresión de que estas comisiones, y por extensión, la justicia transicional, pueden lograr un vasto número de fines (lo cual ignora que, por supuesto, hay una gran diferencia entre el análisis y la transformación).

La cuarta razón que explica el hecho de que la agenda de la justicia transicional se haya ampliado de modo desmedido, en mi opinión, tiene que ver con la migración en el uso de las medidas de los contextos postautoritarios a los contextos post-conflicto (y aun a los contextos de conflicto activo). Con el apoyo de la cooperación internacional, de donantes que quieren hacer algo en situaciones postconflicto, bajo el reclamo de víctimas que piden que sus inmensas necesidades sean atendidas, y con la participación de activistas que circulan globalmente, la política de justicia transicional es transferida de un contexto a otro. Como anoté anteriormente, dicha migración ocurre sin tener en cuenta las dos características del contexto que puede decirse que es el "lugar natural", y ciertamente de origen, de las medidas de justicia transicional. Eventualmente, ante necesidades diferentes existe la tendencia a pensar que las medidas son "elásticas", que pueden ser "estiradas" para servir las necesidades recurrentes en el nuevo contexto de aplicación, y se acaba por atribuirles el potencial correspondiente.

En resumen, el campo enfrenta un entorno probablemente menos favorable que el de hace unas décadas. Enfrenta también retos internos que de alguna forma están relacionados con las razones que lo hicieron exitoso en primer lugar, incluyendo el hecho de defender la implementación de una variedad de medidas y no sólo una, de que algunas de esas medidas se prestan para análisis amplios que incluyen factores estructurales y no sólo individuales, y de que el "paquete" de medidas logró hacerse suficientemente atractivo como para ser "trasplantado" de un contexto a otro. Este reto interno puede ser descrito en términos de diferentes dimensiones de la "coherencia" del campo y se desprende entre otros factores de las tendencias centrífugas entre las diferentes medidas. Tendencias que, por lo demás, se exacerban en contextos de aplicación novedosos y que se traducen, en parte, en la expansión progresiva de la agenda de la justicia transicional sin tener claridad acerca de su capacidad para lograr los nuevos fines que se le atribuyen.

\section{Esbozos de una concepción normativa de la justicia transicional}

Obviamente, lo que los promotores de la justicia transicional pueden hacer por resolver algunos de los retos externos que el campo enfrenta, entre otros, los efectos de una crisis económica internacional, no es mucho. Aun considerando el movimiento del péndulo en el contexto internacional a favor de los economistas, lo que he descrito en términos de la reemergencia del "desarrollismo", las posibilidades son limitadas. Pero especialmente con respecto a este último punto, no son

25 La indiferencia hacia la explicación en las áreas de intervención política es notable. La literatura sobre las intervenciones en el área de la justicia es o descriptiva, o prescriptiva, o justificatoria. En esto tampoco está en una situación peculiar. Este no es el lugar para seguir esta discusión, pero el fenómeno tiene raíces profundas y coincide con el giro hacia la cuantificación en las ciencias sociales, que acabó siendo uno que favoreció no la explicación (en el sentido de la identificación de causas) sino simplemente la descripción de correlaciones. Parte de mi trabajo presente es un intento por regresar al campo de la explicación. 
nulas; si bien la crisis actual en el Medio Oriente y el norte de África, para mencionar tan solo un ejemplo, tiene una dimensión económica relativa al desempleo y a la ausencia de oportunidades, particularmente entre los jóvenes, también tiene una dimensión importante de justicia. Esta dimensión en realidad coincide con la agenda de la justicia transicional por lo menos en dos puntos relacionados entre sí: las demandas tienen que ver también con el respeto a los derechos humanos de los ciudadanos y con la legitimidad de los diferentes regímenes. Todo esto resalta la importancia de insistir en que el desarrollo involucra una dimensión de justicia. Particularmente, que en contextos en los cuales han ocurrido violaciones sistemáticas de derechos no hay tal cosa como un "novum ordum", que no es posible un "borrón y cuenta nueva" y que, por tanto, en la medida en la que se espere que los ciudadanos hagan parte de un orden político común (lo cual en últimas, como queda visto una vez más, no puede lograrse de forma sostenible mediante la represión pues ésta asegura, a lo sumo, la estabilidad temporal, pero no la participación), la historia de abusos no puede ser ignorada indefinidamente. En ese sentido, el reto representa al mismo tiempo una oportunidad para la justicia transicional26.

Los retos que he llamado "internos" al campo son, naturalmente, más fáciles de superar; al menos dependen de la forma como el campo usa sus recursos propios. Arriba describí estos retos en términos de dimensiones diferentes de la coherencia interna y externa del campo, de la forma como articula la relación entre sus diferentes componentes, y entre el campo en general e intervenciones en otras esferas que obviamente hacen parte de procesos de transformación política como la seguridad y el desarrollo.

No quiero sugerir que problemas que definitivamente tienen una dimensión práctica pueden ser totalmente resueltos a través de la teoría, pues esto sería una exageración. Pero, por otro lado, no puede ni subestimarse el grado inmenso de subteorización de la justicia transicional, un campo que, como he dicho, nació de la práctica y que desde entonces, aun en los ámbitos académicos, ha estado dominado por juristas y politólogos no especialmente proclives a la teorización normativa. Tampoco puede subvalorarse la contribución que los esfuerzos teóricos pueden hacer a un campo "emergente". La teoría puede hacer contribuciones directamente relevantes a algunos de los retos mencionados anteriormente. En primer lugar, desde los tiempos de Aristóteles, el punto principal de la teoría es articular vínculos entre fenómenos cuya relación ha causado perplejidad, lo cual por supuesto puede contribuir a responder a la primera dimensión del reto de la coherencia, explicando la relación entre los diferentes elementos de una política de justicia transicional. En segundo lugar, la teoría normativa contribuye a aclarar la extensión y las implicaciones de los compromisos que aceptamos; así como la teoría constitucional, por ejemplo, contribuye a aclarar las consecuencias que se desprenden de comprometerse con el principio del debido proceso ${ }^{27}$, la actividad teórica puede contribuir a dilucidar las implicaciones del compromiso repetido una y otra vez por los defensores de la justicia transicional con la norma de derecho (rule of law). Estas contribuciones, colectivamente, pueden, en tercer lugar, ayudar a establecer los vínculos entre la justicia transicional y otros campos de intervención, uno de los retos más urgentes que en mi opinión el campo enfrenta. La concepción normativa de la justicia transicional que esbozaré en lo que sigue ${ }^{28}$ se centra además en fijar los fines u objetivos apropiados de la justicia transicional, lo

26 El hecho de que las transiciones del Medio Oriente y el Norte del África sean más parecidas a las transiciones postautoritarias que a las postconflicto también tiene ventajas para el campo desde mi punto de vista.

27 El trabajo de Ronald Dworkin es un ejemplo particularmente efectivo de esta función de la teoría constitucional. Véase, por ejemplo, su "What is Law" en DWORKIN, Ronald. Law's Empire. Boston, Harvard University Press, 1986, y como ilustración de su aplicación a un tema concreto, DWORKIN, Ronald. Judge Roberts on Trial. New York Review of Books. 52(16), 2005.

28 Esta concepción la he desarrollado en detalle en DE GREIFF, Pablo. Theorizing Transitional Justice. En: WILLIAMS, Melissa y NAGY, Rosemary (Eds.). Transitional Justice. Nomos vol. L. New York University Press (De próxima publicación). 
cual contribuye a solucionar el otro gran problema anotado anteriormente que afecta la coherencia del campo, el de la proliferación sin límites de los fines que se le atribuyen.

La concepción normativa, una construcción teórica, es fácil de resumir:

La justicia transicional se refiere a un conjunto de medidas que pueden ser implementadas para hacer frente al legado de los abusos masivos de derechos humanos, donde "hacer frente al legado" de tales abusos significa, en primer lugar, demostrar la vigencia de las normas de derechos humanos que fueron sistemáticamente violadas. Una lista no exhaustiva de tales medidas incluye: el enjuiciamiento penal, la búsqueda de la verdad, las reparaciones y la reforma institucional. Lejos de ser componentes de una lista al azar (random list), estas medidas son partes de la justicia transicional en virtud de compartir dos objetivos o fines "mediatos", a saber, proporcionar reconocimiento a las víctimas y promover la confianza cívica; y un objetivo final, contribuir al fortalecimiento de la norma de derecho democrática (democratic rule of law ${ }^{29}$.

Brevemente, la idea central es que los diferentes elementos de una política comprehensiva de justicia transicional están vinculados unos con otros por el hecho de que las diferentes medidas puede pensarse que comparten ciertos objetivos o fines. El fin último de la justicia transicional, por supuesto, es promover la justicia. El problema con esta afirmación es que es demasiado abstracta para ser realmente útil, aun si se intenta especificar el concepto general de justicia apelando a la noción de que ésta consiste en "darle a cada quien lo que merece", o a estrechar los vínculos entre el esfuerzo y el éxito.

No obstante, en un espíritu reconstructivo o interpretativo, y a un nivel medio de abstracción, puede argumentarse que las diferentes medidas de justicia transicional comparten dos fines "mediatos" y un fin "último". El argumento es que las medidas de justicia transicional pueden ser vistas como intervenciones que tienen como fines "mediatos" la promoción del reconocimiento a las víctimas y la confianza cívica, y el fortalecimiento de la norma de derecho democrática como fin "último". Los calificativos "mediato" y "último" requieren aclaración, pues no deben entenderse en términos cronológicos, sino, en un sentido que paso a explicar, en términos de la (in)suficiencia causal de una medida particular para lograr el fin que se le atribuye. El objetivo "inmediato" de una medida de justicia transicional particular sería aquel que, en teoría, puede ser alcanzado gracias a esa intervención concreta (independientemente del tiempo que haga falta para que así sea). Así, por ejemplo, quienes piensan que la disuasión es un objetivo inmediato de la justicia penal consideran que los juicios pueden producir ese efecto (aunque no sea, necesariamente, un efecto a corto plazo).

"Mediato" y "final" se refieren, por tanto, a grados de separación de esta posición. Los fines mediatos de una medida son aquellos que es razonable suponer que la implementación de la medida contribuye a lograr pero no independientemente de la implementación de otras medidas paralelas. La medida no es causalmente suficiente para lograr su fin por sí sola. Así, por ejemplo, las reparaciones pueden contribuir a que las víctimas se sientan reconocidas. No obstante, casi con seguridad, no pueden satisfacer por sí mismas el conjunto de demandas de reconocimiento de las víctimas. Para lograr este objetivo será también necesaria la implementación de otras medidas.

En cuanto al uso que estoy haciendo aquí del término "objetivos finales" o "fines últimos", no se trata de fines "en virtud de los cuales se hace todo lo demás", como los define Aristóteles en el

29 En DE GREIFF, Pablo. Theorizing Transitional Justice. En: WILLIAMS, Melissa, NAGY, Rosemary y ELSTER, Jon (Eds.). Transitional Justice. Nomos vol. LI. New York University Press (De próxima publicación) defiendo la posición de que la "reconciliación" (entendida en términos de confianza) es otro fin último de la justicia transicional. Por razones de espacio, omito aquí referencia a este punto. 
libro I de la Ética Nicomaquea, sino fines cuya consecución está causalmente aún más lejana y, por tanto, cuya realización depende de la contribución de un número aún mayor de factores cuyo papel, relativamente hablando, aumenta en importancia. La distinción entre los fines, entonces, la establezco apelando no a uno, sino a dos ejes: no sólo el número de factores contribuyentes, sino su importancia relativa para la realización del objetivo en cuestión. Mientras que no es impensable afirmar que las medidas de justicia transicional, si son diseñadas e implementadas de forma "coherente" -esto es, articulando claramente las formas como se relacionan entre sí positiva y negativamente, e intentando maximizar las sinergias- pueden contribuir a que los ciudadanos confíen en sus instituciones, es obvio que fortalecer la democracia (un fin "último") requerirá la intervención de un número mayor de factores. En esta mezcla de políticas, la importancia (en el sentido de suficiencia causal) de las medidas de justicia transicional puede acabar siendo relativamente baja, comparada, por ejemplo, con reformas constitucionales amplias -que incluyan, por ejemplo, una división de poderes efectiva, garantías a la oposición política, etc.- o programas ambiciosos de restructuración económica.

Regresando ahora al modelo, esta es una concepción sistemática precisamente porque no atribuye a las medidas fines que, por deseables que sean, pueden, sin embargo, estar solo casualmente relacionados con las primeras. Lo que hace razonable pensar que el proveer reconocimiento, promover la confianza cívica y fortalecer la norma de derecho democrática son los fines de la justicia transicional (fines que describiré en el apartado (a), que sigue) no es solamente que estos objetivos están conceptualmente relacionados entre sí (b), sino, más importante aún, que guardan relaciones estrechas con la justicia (c), y, por supuesto, que es posible dar una explicación de la forma en la que las medidas son en principio funcionalmente adecuadas para lograr los fines en cuestión $(\mathrm{d})^{30}$.

\section{(a) Los fines de la justicia transicional}

Antes que nada hace falta caracterizar, así sea brevemente, estos fines. Por razones de espacio, comienzo aquí más estipulando que argumentando ${ }^{31}$. A un nivel intermedio de abstracción -más alto que la mera descripción de los fines inmediatos que se alega que las diferentes medidas persiguen, pero más bajo que la afirmación según la cual todas ellas buscan "hacer justicia"puede decirse que las diferentes medidas de justicia transicional buscan el reconocimiento de las víctimas. ${ }^{32}$ El tipo de reconocimiento relevante pasa por reconocer su estatus como víctimas, reconocer los abusos de los que fueron sujetas, dar espacio público a sus historias, y "reversar" la marginalización de la cual tradicionalmente han sufrido. Pero esto no es todo; en realidad, más importante aún es reconocer su estatus como derechohabientes, en últimas, como copartícipes en un proyecto político común, es decir, como ciudadanos. El punto es que la penalización de

30 Que las medidas sean en principio adecuadas para lograr los fines en cuestión no quiere decir que su implementación garantice el logro de los fines. El logro de los fines es por supuesto asunto empírico que no puede decidirse a priori.

31 Pero en DE GREIFF, Pablo. Theorizing Transitional Justice. En: WILLIAMS, Melissa y NAGY, Rosemary (Eds.). Transitional Justice. Nomos vol. L. New York University Press (De próxima publicación) articulo en detalle los argumentos relevantes.

32 Sobre la noción de reconocimiento, véase, entre otros, HONNETH, Axel. The Struggle for Recognition: The Moral Grammar of Social Conflicts. Cambridge, MIT Press, 1995 [trad. esp. HONNETH, Axel. La lucha por el reconocimiento: por una gramática moral de los conflictos sociales. Barcelona, Crítica, 1997], su contribución en HONNETH, Axel y FRASER, Nancy. Redistribution or Recognition: A Political-Philosophical Exchange. New York, Verso, 2003 [trad. esp. HONNETH, Axel y FRASER, Nancy. ¿Redistribución o reconocimiento? Madrid, Ediciones Morata, 2006], y las de varios autores, así como dos respuestas bien meditadas del propio Honneth, en VAN DEN BRINK, Bert y OWEN, David (Eds.). Recognition and Power. New York, Cambridge University Press, 2007. Una revisión especialmente lúcida de las mismas puede encontrarse en ZURN, Christopher F. Identity or Status? Struggles Over "Recognition" in Fraser, Honneth, and Taylor. Constellations 10: 519-537, 2003. 
las violaciones, el esclarecimiento histórico, la reparación y las medidas de reforma institucional -especialmente aquellas que tienen que ver con los instrumentos de la justicia y la protección que fallaron de forma tan abismal en su obligación de defender los derechos de las víctimastienen como fin mediato reconocer a las víctimas en tanto que víctimas, pero, primordialmente, en tanto que derechohabientes.

En segundo lugar, las medidas de justicia transicional puede decirse que buscan promover la confianza cívica. La confianza cívica, tanto horizontal (la de los ciudadanos entre sí) como vertical (la de los ciudadanos en las instituciones del Estado), depende, finalmente, de la percepción de la relevancia de ciertas normas; la confianza no es lo mismo que la regularidad o previsibilidad. Decimos que confiamos en alguien no cuando podemos predecir su comportamiento y "contar con él", sin más. El comportamiento de regímenes autoritarios y corruptos, por ejemplo, es bastante predecible, y sin embargo no es confiable. Confío en alguien cuando cuento con que en su razonamiento sobre qué opción tomar, ciertas normas que compartimos juegan un papel determinante. Confío en instituciones cuando cuento con que quienes las rigen y las operan toman sus decisiones de acuerdo con esas normas. De nuevo, el argumento es que a un nivel intermedio de abstracción, puede decirse que las medidas de justicia transicional tienen como fin mediato promover la confianza cívica en el sentido descrito; pretenden afirmar las normas alrededor de las cuales se puede fundamentar la fiabilidad de las instituciones, y en la medida en la que las instituciones públicas requieren cierto grado de consentimiento generalizado (entre otras cosas para el desplazamiento de recursos de todos), la fiabilidad de los ciudadanos entre sí.

En tercer lugar, y tomando un giro abstractivo más, puede decirse que todas las medidas de justicia transicional tienen como objetivo último -de nuevo no en el sentido justificatorio sino de (in)suficiencia causal- el fortalecimiento de la norma de derecho democrática. En el orden de la justificación es la justicia y no la norma de derecho lo que justifica la implementación de estas medidas. Pero en el orden explicativo, que es el que quiero comenzar a ocupar en este artículo, tiene ventajas articular el punto de esta manera. De prácticamente todos los instrumentos de justicia transicional se ha dicho que tienen como objeto fortalecer la norma de derecho. El punto que me interesa enfatizar aquí es que no es sólo la norma de derecho en el sentido formal, es decir, el de la "justicia como regularidad" -según la adecuada expresión utilizada por Rawls para referirse a las concepciones formalistas de la norma de derecho ${ }^{33}$ - con la cual la justicia transicional tiene un compromiso. De hecho, las comisiones de verdad y reconciliación tanto de Chile como de Sudáfrica criticaron, en su momento, la concepción formalista de la norma de derecho reinante en ambos países ${ }^{34}$. La razón debe ser clara: a pesar de la inmensa importancia de las restricciones al ejercicio del poder que se desprenden de una concepción formalista de la norma de derecho, incluyendo la generalidad, publicidad y no retroactividad de la ley, estas restricciones no fueron suficientes para garantizar efectivamente los derechos de los ciudadanos.

Puesto que los defensores del formalismo pueden alegar que este último punto no es en realidad un argumento, sino una forma de redescribir la supuesta insuficiencia de la posición que defienden, ofrezco dos argumentos adicionales a favor de entender el compromiso de la justicia transicional con una noción más sustantiva de la norma de derecho.

33 RAWLS, John. A Theory of Justice. Cambridge, Harvard University Press, 1971, p. 207.

34 Ver Report of the Chilean National Commission on Truth and Reconciliation, esp. vol. 1, pp. 118ff y en vol. 2, "Behavior of the Courts Toward the Grave Human Rights Violations that Occurred between September 11, 1973 and March 11, 1990" (Indiana: University of Notre Dame Press, 1993), vol. 2 pp. 859ff. Truth and Reconciliation Commission of South Africa Report (SATRC), "Institutional Hearing: The Legal Community" (London: Macmillan Reference Limited, 1998), Vol. 4, Ch. 4. Véase también DYZENHAUS, David. Judging the Judges, Judging Ourselves. Oxford, Hart Publishing, 1998. 
El primero es de naturaleza conceptual y es ejemplo de la forma como la teoría normativa sirve para aclarar el alcance y las implicaciones de nuestros compromisos. En este caso el argumento establece vínculos entre los derechos típicamente protegidos aun por una concepción formalista de la ley y una gama más amplia de derechos sustantivos que incluye los derechos a la participación. Este argumento, que se centra no sólo en los procesos de aplicación de la ley, sino de la generación de la misma, trata de esclarecer la conexión fundamental entre el constitucionalismo, entendido en sentido formalista, y la democracia. En resumen, el argumento es que si el objetivo es establecer relaciones mediadas por derechos -en vez de por la virtud o la gracia de los gobernantes- tanto los derechos civiles tradicionales (plasmados en leyes que satisfacen las condiciones formales de la idea de la norma de derecho) como los derechos a la participación política son necesarios. Si el soberano siempre puede suspender el "derecho" a la privacidad, por ejemplo, o cambiar su definición de forma que lo haga irrelevante, es claro que aquí no se está hablando de un derecho. Tanto la fuerza como el contenido de un derecho -es decir, su estatus como derecho- aun de uno civil, individual, dependen de la posibilidad de restringir la capacidad del soberano de suspenderlo o redefinirlo a su parecer sin el consentimiento de los ciudadanos. Por otro lado, el derecho a la participación política, en ausencia de derechos civiles como el de la privacidad (que protege, entre otras, algunas de las esferas en las cuales los ciudadanos pueden desarrollar sus preferencias personales), pierde también su estatus como derecho y se convierte en mero instrumento de refrendación ${ }^{35}$.

El segundo argumento a favor de la afirmación según la cual el compromiso de la justicia transicional no es con una concepción formalista de la norma de derecho, sino con la norma de derecho democrática, es el resultado de un esfuerzo explicativo, del intento de entender cómo funcionan las medidas de justicia transicional. Nuevamente aquí no puedo más que esbozar el $\operatorname{argumento}^{36}$. En últimas cuando se intenta entender los "mecanismos sociales" ${ }^{37}$ a través de los cuales las medidas de justicia transicional surten cualesquiera efectos pueden lograr, hay dos mecanismos que son básicos: uno es la afirmación de normas, y otro es su capacidad para articular y desarticular "grupos sociales".

Me concentro en el segundo mecanismo por el momento: las medidas de justicia transicional son efectivas -en la (modesta) medida en la que lo son- en virtud de su capacidad de catalizar la formación de ciertos grupos; no hay país del mundo en donde se haya propuesto una discusión seria acerca de establecer una de las medidas de justicia transicional en donde esto no haya llevado a la formación de múltiples grupos de la sociedad civil, incluyendo víctimas, que defienden o combaten particularidades de la propuesta. Estas medidas tienen también la capacidad (más débil) de desarticular grupos o por lo menos de obstaculizar su funcionamiento y desarrollo ${ }^{38}$. El punto es que la efectividad de las medidas de justicia transicional presupone cierto grado de

35 El argumento más convincente de esta relación entre la democracia y la norma de derecho es el ofrecido por Jürgen Habermas en HABERMAS, Jürgen. On the Internal Relationship between the Rule of Law and Democracy. En: CRONIN, Ciaran y DE GREIFF, Pablo (Eds.). The Inclusion of the Other. Cambridge, MIT Press, 1998, y en HABERMAS, Jürgen. Legitimation Through Human Rights En: DE GREIFF, Pablo y CRONIN, Ciaran (Eds.). Global Justice and Transnational Politics. Cambridge, MIT Press, 2002. La concepción constructivista del desarrollo de Amartya Sen, a pesar de que se centra más en la libertad que en los derechos, puede tomarse también como fuente de apoyo para el argumento que resumo en este párrafo. SEN, Amartya. Development as Freedom. Oxford, Oxford University Press, 2001.

36 Ver mi contribución a DE GREIFF, Pablo (Ed.). How Things Work: Explaining Transitional Justice Interventions (De próxima publicación).

37 Ver HEDSTRÖM, Peter y SWEDBERG, Richard (Eds.). Social Mechanisms. New York, Cambridge University Press, 1998.

38 Esta es, a mi juicio, una mejor manera de entender los efectos de la penalización y los procedimientos de exclusión o "depuración" (vetting) que la disuasión (deterrence), entre otras porque no apela ni a disposiciones ni a estados mentales, y por lo tanto no depende de cálculos (especulaciones) de la probabilidad de reincidencia en el crimen. Esta explicación 
apertura democrática en las sociedades en las cuales se implementan, que depende de la posibilidad de realizar el potencial que las medidas tienen para articular y desarticular grupos sociales. Esta "plasticidad" es una de las características de las sociedades abiertas, una apertura que las medidas pueden contribuir a catalizar, pero de las cuales ellas también dependen; en una sociedad completamente cerrada a la formación y desarticulación de grupos es dudoso que las medidas tuvieran mayor impacto. Esta compleja relación entre causa y consecuencia es precisamente lo que pretendo expresar diciendo que la norma de derecho democrática es un fin último de la justicia transicional: sería un error pensar que las medidas de justicia transicional por sí solas son causalmente suficientes para establecer la democracia -lo cual queda claro entre otras razones porque el cambio de régimen normalmente precede la implementación de las medidas-, pero igualmente sería un error ignorar por completo la contribución que estas medidas pueden hacer al fortalecimiento de la norma de derecho democrática. A este punto regresaré más adelante.

\section{(b) La relación conceptual entre los fines}

Habiendo caracterizado los diferentes fines de la justicia transicional, retorno al argumento. Recuérdese que parte del punto de desarrollar una construcción teórica es el de trazar vínculos sistemáticos entre fenómenos aparentemente independientes. La concepción de justicia transicional que esbozo aquí es particularmente densa en interconexiones; busca explicar la relación entre los diferentes elementos de la justicia transicional en torno a una serie de fines que esos elementos se puede decir persiguen. El siguiente paso consiste en mostrar, precisamente, las relaciones entre estos tres fines, y luego, las relaciones entre éstos y el concepto de justicia.

Primero, existe una relación estrecha entre el reconocimiento, la confianza cívica y la norma de derecho democrática. La estrategia que sigo consiste en identificar la naturaleza profundamente normativa de estos tres conceptos; "normativa" no sólo en el sentido que contrasta con "descriptiva" o "fáctica", sino que se refiere a su dependencia de ciertas normas. Aun el reconocimiento de las víctimas en tanto que víctimas depende no tanto de reconocer su sufrimiento, como he dicho, sino más aun, la magnitud de las ofensas, de las violaciones de derechos que resistieron. La referencia a normas que subyace a la noción de reconocer a las víctimas como derechohabientes es explícita y no necesita más explicación; los derechos formalmente establecidos emergen de un entramado de normas identificables. De la misma manera, expliqué la confianza cívica en términos, precisamente, del lugar que ciertas normas juegan en la decisión sobre qué opciones tomar. Y por último, no es sólo que la norma de derecho, en general, obviamente apela a normas, sino que una de las razones por las cuales pienso que la justicia transicional implica un compromiso con una noción sustantiva de la norma de derecho es que en contextos modernos una regla es reconocida como una ley, para comenzar, sólo cuando quienes están sujetos a ella reconocen, desde una perspectiva evaluativa la capacidad de la regla para guiar su comportamiento [normen] sino, más importante aún, su autoridad. En contextos modernos las reglas adquieren autoridad sólo cuando son percibidas como si fueran "nuestras", el resultado de lo que he llamado dinámicas de inclusión y propiedad que hacen a los sujetos de la ley al mismo tiempo sus autores ${ }^{39}$.

Más allá de la naturaleza común de los conceptos que definen los objetivos de la justicia transicional, es decir de su naturaleza normativa, el punto es que estos fines hacen referencia a las mismas normas: una forma de ver la relación entre el reconocimiento y la confianza cívica es observando

es válida también para algunos de los efectos del esclarecimiento, en la medida en la que la transparencia obstaculiza el desarrollo de ciertos abusos.

39 Véase DE GREIFF, Pablo. Truth-Telling and the Rule of Law. En: BORER, Tristan A. (Ed.). Telling the Truths, Truth Telling and Peacebuilding in Post-Conflict Societies. Notre Dame, University of Notre Dame Press, 2006. 
que el reconocimiento implica el respeto por cierto estado [standing], por un estatus ${ }^{40}$. Este estado es el de un sujeto legal -y por ende uno con derechos- y que es sobre esa base sobre la cual las personas pueden desarrollar ciertas actitudes y disposiciones en sus interacciones mutuas y en sus interacciones con instituciones, aquellas que caracterizan la confianza. El estatus en cuestión, el de ciudadano, y las disposiciones que lo acompañan, descansan, a su vez, sobre el entramado de normas que constituyen la norma de derecho democrático.

\section{(c) Los fines de la justicia transicional y la justicia}

Aun habiendo establecido que es razonable atribuirle a las diferentes medidas de justicia transicional los fines que les estoy atribuyendo, y aun si hubiera establecido que las medidas son adecuadas para lograr esos fines (lo cual sólo intentaré en el siguiente apartado), quedaría por resolver qué tienen ellos que ver con la justicia, cómo contribuyen a lo que concedí desde el principio que es, en últimas, el punto de establecer estas medidas, es decir "servir a la justicia". Sería un problema, desde mi punto de vista, si la concepción de justicia transicional articulada aquí sólo pudiera establecer vínculos con fines que por deseables que fueran no estuvieran directamente vinculados con la justicia.

De hecho, sin embargo, los tres fines mencionados tienen una relación compleja con la justicia, o, para ser más preciso, con los intentos de promover la justicia a través de medios legales. Todos estos fines pueden considerarse como dimensiones o, simultáneamente, como condiciones y consecuencias de los esfuerzos por dar expresión concreta a través de sistemas legales a una noción necesariamente más abstracta de justicia. El argumento es, en resumen, que un sistema de justicia (uno basado en leyes, al menos), es decir, un sistema de derechos efectivos y legítimos es inconcebible sin niveles mínimos de reconocimiento, confianza y participación política. Pero el punto no es solamente que un sistema de derechos presupone niveles mínimos de estos tres factores sino que también los cataliza; los sistemas de justicia de este tipo también estimulan y fortalecen el reconocimiento, la confianza y la participación política. Si esto es correcto, la relación entre estos fines y la justicia es tan estrecha como compleja.

Nuevamente un esbozo tendrá que ser suficiente. Tanto el reconocimiento como la confianza puede decirse que son precondiciones y consecuencias de la justicia, al menos de los esfuerzos por obtener justicia mediada por la ley. El derecho funciona a partir de la concepción de las personas como sujetos legales, esto es, de reconocer cierto estatus, el de derechohabientes, a individuos (y ciertas colectividades) ${ }^{41}$. Así pues una condición de la acción legal encaminada a la búsqueda de la justicia es el reconocimiento de este estatus, lo cual explica la importancia de las luchas legales por el reconocimiento, por la "emancipación" (enfranchisement), y la tragedia que suponen las diversas maneras formas de fracaso de esta forma básica de reconocimiento de los individuos como sujetos legales, como sujetos de derechos ${ }^{42}$. Pero si es adecuado decir que el reconocimiento es una condición de la justicia, no lo es menos decir que el reconocimiento es una consecuencia de la justicia; el funcionamiento de un sistema legal, a lo largo del tiempo,

40 Véase FRASER, Nancy. Rethinking Recognition. New Left Review. 3, 2000.

41 Como lo dice Jürgen Habermas, "El medio legal como tal presupone derechos que definen el estatus legal de las personas como sujetos de derechos". HABERMAS, Jürgen. Between Facts and Norms. Cambridge, MIT Press, 1996, p. 119 [trad. esp. HABERMAS, Jürgen. Facticidad y validez. Madrid, Trotta, 1998.

42 El énfasis que pone Hannah Arendt sobre la inexistencia del Estado como un factor explicativo fundamental de los grandes desastres del siglo XX estaría, desde esta perspectiva, completamente justificado. Véase, por ejemplo, "Decline of the Nation-State: End of the Rights of Man", en ARENDT, Hannah. The Origins of Totalitarianism. New York, Harcourt, 1985 [trad. esp. ARENDT, Hannah. Los orígenes del totalitarismo. Madrid: Taurus, 1997. 
facilita también la extensión de reconocimiento a aquellos que no eran previamente reconocidos, precisamente gracias a la dinámica de inclusión que mencioné anteriormente ${ }^{43}$.

Igualmente, la confianza es también una condición y una consecuencia de la justicia. Por una parte, el funcionamiento de los sistemas legales depende de formas complejas de confianza. Los sistemas legales penales dependen de la disposición de los ciudadanos de denunciar los crímenes de los que son testigos o víctimas. Y esta disposición de denunciar descansa, por supuesto, sobre su confianza en que el sistema producirá de manera fiable los resultados esperados. Este es un tipo complejo de confianza: en la investigación policial, en la eficiencia del sistema judicial, en la honestidad de los jueces, en la independencia del sector judicial ( $y$, por tanto, en la disposición del Ejecutivo de proteger y promover su independencia), en la sabiduría, aunque sea mínima, del Legislativo, y en la severidad (pero probablemente también y al mismo tiempo en la humanidad) del sistema penitenciario, etc. Sobra decir que cada uno de estos objetos de confianza podría ser analizado más detalladamente.

Por otra, un sistema legal no simplemente cuenta con la confianza preexistente de los ciudadanos, entre ellos y hacia el sistema legal. Los sistemas legales, cuando funcionan bien, también catalizan la confianza, una vez más, entre los ciudadanos y de estos hacia el sistema; al estabilizar las expectativas, los sistemas legales disminuyen los riesgos y costos de confiar en los otros, particularmente cuando son extraños. Si acumula un historial de éxito en la resolución de conflictos entre los ciudadanos, un sistema legal cataliza su confianza hacia las instituciones legales, a las cuales recurrirán con mayor frecuencia para resolver las diferencias que surgen entre ellos.

Por último, que la norma de derecho democrática es una condición y una consecuencia del intento por conseguir la justicia a través de medios legales requiere de menos explicación dados los argumentos anteriores; la noción misma de un sujeto de derecho descansa sobre la forma legal, pero, como vimos, el punto no se reduce a que la vigencia de la ley depende también de la participación de los ciudadanos, sino que una vez establecida la ley es normalmente utilizada no sólo para estabilizar sino también para ampliar el alcance del régimen de derechos.

Resumiendo, bajo condiciones modernas el reconocimiento, la confianza cívica y la norma de derecho democrática son tanto condiciones como consecuencias de los sistemas formales de justicia; la búsqueda de la justicia depende de niveles mínimos de reconocimiento mutuo, de confianza especialmente en las instituciones y de respeto por derechos tanto individuales como de participación. Por otro lado, estos sistemas no sólo cuentan con esos niveles mínimos sino que los estabilizan, los fortalecen y los aumentan ${ }^{44}$. Los dos objetivos mediatos que le he atribuido a las medidas de justicia transicional, proveer reconocimiento y promover la confianza cívica, y el objetivo final, fortalecer la norma de derecho democrática, entonces, están de hecho fuertemente relacionados con la justicia y no son, por tanto, metas u objetivos únicamente deseables.

\section{(d) La adecuación funcional de las medidas de justicia transicional}

El último punto pendiente para darle plausibilidad a una concepción de la justicia transicional que gira alrededor de la atribución de ciertos objetivos a cada una de sus elementos es mostrar que las medidas son funcionalmente adecuadas para lograrlos. Esto puede hacerse de diferentes formas, entre otras, por medio de análisis de casos que demuestren que en contextos concretos

43 Véase DE GREIFF, Pablo. Truth-Telling and the Rule of Law. En: BORER, Tristan A. (Ed.). Telling the Truths, Truth Telling and Peacebuilding in Post-Conflict Societies. Notre Dame, University of Notre Dame Press, 2006.

44 De nuevo, esta no es una predicción, sino un argumento acerca de potenciales funcionales. Si esos potenciales son actualizados o no en casos particulares sólo puede establecerse empíricamente. 
la implementación de las medidas efectivamente ha servido esos fines. Aquí no puedo hacer referencia a la amplia literatura -académica y "práctica" - que podría utilizarse para este efecto ${ }^{45}$, por razones de espacio pero también de enfoque; mi pretensión no es sólo prescriptiva, no es esencialmente descriptiva, sino, recuérdese, también explicativa. Lo que haré, entonces, es ofrecer una explicación, un recuento razonable de los pasos que pueden llevar de la implementación de las diferentes medidas al logro de cada uno de los fines. Estos "recuentos", consistentes con la idea de "mecanismos sociales", son causales pero no apelan a leyes universales y por lo tanto no implican la necesidad; es decir, la pregunta acerca de si la implementación de las medidas en efecto lleva al fin en cuestión sigue abierta, como debe ser, a la verificación empírica. Los recuentos, consistentes también con la idea de que se trata de reconstruir las cadenas causales de objetivos que no son inmediatos, de fines que se logran sólo mediante la intervención de varias medidas en consecuencia no son unicausales. Luego tampoco deben crear la presunción de que las medidas de justicia transicional ni individual ni colectivamente son suficientes por sí mismas para generar estos fines.

En resumen, el argumento es el siguiente: las diversas medidas de justicia transicional contribuyen a la institucionalización del reconocimiento de los individuos como ciudadanos con igualdad de derechos a través de las siguientes cadenas: la justicia penal negando la demanda implícita de superioridad contenida en el comportamiento del criminal, negación que toma la forma de una condena que reafirma, finalmente, la importancia de las normas que garantizan la igualdad de derechos para todos ${ }^{46}$. Los procesos de esclarecimiento de la verdad histórica proporcionan reconocimiento de formas que es posible no hayan sido todavía mejor articuladas de lo que lo fueron en su día en la diferencia propuesta por Thomas Nagel entre conocimiento (knowledge) y admisión pública de ese conocimiento (acknowledgment), cuando argumentó que, a pesar de que las comisiones de la verdad rara vez desvelan hechos que no fueran previamente conocidos, siguen haciendo una contribución indispensable al admitir públicamente esos hechos ${ }^{47}$. Este tipo de admisión es importante, precisamente, porque constituye una forma de reconocer la importancia y el valor de las personas -otra vez, como individuos, como ciudadanos y como víctimas. Las reparaciones funcionan en la medida en la que logren convertirse en manifestaciones materiales y simbólicas de que la violación de derechos no es inconsecuente para nadie: que el Estado y sus miembros la consideran lo suficientemente importante como para invertir en el resarcimiento tanto recursos económicos como "capital moral". Y que como esa violación tiene consecuencias para las víctimas, tomar en serio esas violaciones y el bienestar de las víctimas implica crear (con su participación, pues el reconocimiento no es solo algo que se "concede") programas especiales para ellas. Por último, la reforma institucional, con los procesos de descalificación como punto de partida, produce reconocimiento, en la medida en la que confirma la vigencia de la norma que afirma que los funcionarios del Estado son servidores públicos y que de esto se desprenden reglas que incluyen normas de permanencia en el empleo, de ascensos y de despidos que crean

45 Que por supuesto mostraría logros pero no "revolucionarios". La justicia transicional en mi opinión es campo de triunfos graduales.

46 Véase, por ejemplo, HAMPTON, Jean. The Moral Education Theory of Punishment. Philosophy and Public Affairs (1981): 209-238, 1981, y HAMPTON, Jean. A New Theory of Retribution. En: FREY, R.G. y MORRIS, Christopher W (Eds.). Liability and Responsibility. Cambridge, Cambridge University Press, 1991. Véase también DE GREIFF, Pablo. Deliberative Democracy and Punishment. Buffalo Criminal Law Review 5(2): 101-130, 2002.

47 Thomas Nagel argumenta que hay "una diferencia entre el conocimiento (knowledge) y el reconocimiento (acknowledgment). El reconocimiento sería lo que le sucede y sólo puede sucederle al conocimiento cuando se sanciona de forma oficial, es decir, cuando se hace parte de escena cognitiva pública" citado por Lawrence Weschler, "Afterword", en Aspen Institute. State Crimes: Punishment or Pardon. Washington, D.C., 1989, p. 93. 
las condiciones bajo las cuales los ciudadanos pueden relacionarse los unos con los otros y con las autoridades como iguales.

Ahora bien, las medidas de justicia transicional puede pensarse que promueven la confianza cívica de las siguientes formas: los juicios penales mediante la reafirmación de las normas que los perpetradores han violado, mensaje que es particularmente efectivo si los blancos de la actividad penal son miembros de antiguas élites acostumbradas a utilizar la justicia como instrumento de poder y por lo tanto a sus miembros como "intocables". Los procesos de esclarecimiento de la verdad sobre el pasado pueden promover la confianza cívica en la medida en que responden a las ansiedades de aquellos cuya confianza ha sido destrozada como consecuencia de las experiencias de violencia y abuso que han vivido, quienes razonablemente continúan temiendo que el pasado pueda repetirse. Su miedo específico puede provenir de la sospecha de que la identidad política presente de los (o de algunos) ciudadanos ha sido conformada en torno a valores que hicieron posibles los abusos Un esfuerzo institucionalizado para confrontar el pasado puede ser visto por aquellos que estaban antes en el polo receptor de la violencia como un esfuerzo, hecho de buena fe, de comprender los patrones de socialización a largo plazo y, en este sentido, iniciar un nuevo proyecto político alrededor de normas y valores que, ahora sí, son realmente compartidos ${ }^{48}$. Las reparaciones pueden promover la confianza cívica al demostrar la seriedad con la que las instituciones se toman en el presente la violación de los derechos de los ciudadanos. Una seriedad que se pone de manifiesto, por decirlo muy gráficamente, por el hecho de que el "dinero habla por sí solo", que incluso en condiciones de escasez, el Estado responde a la obligación de financiar programas en beneficio de aquellos que fueron con anterioridad, no sólo marginados, sino también violentados y maltratados. Finalmente, la descalificación puede inducir confianza cívica no sólo "renovando el personal" de las instituciones, sino demostrando, con ello, un compromiso con las normas sistémicas que regulan la contratación y promoción de los empleados, la supervisión disciplinaria, la prevención del tráfico de influencias, etc ${ }^{49}$.

Finalmente, las formas como las medidas de justicia transicional contribuyen a lograr el fortalecimiento de la norma de derecho son en principio más obvias: el argumento general es que los juicios que se llevan a cabo con todas las garantías procesales y sin dejar fuera del brazo de la justicia a quienes ejercieron el poder en el pasado demuestran con acierto la generalidad de la ley; que los ejercicios de búsqueda de la verdad que contribuyen a entender las múltiples maneras en las que los sistemas legales fracasaron a la hora de proteger los derechos de los ciudadanos proporcionan una base sobre la que, en contraposición, pueden comportarse los sistemas legales en el futuro; que los programas de reparaciones que tratan de desagraviar la violación de derechos sirven para ejemplificar, aun si es ex post facto, el compromiso con la idea de que las normas legales importan; y, por último, que las medidas de reforma institucional, incluso aquellas que simplemente descalifican a quienes abusaron de su posición, contribuyen a hacer que los sistemas del estado de derecho se vuelvan operativos, aunque sea de manera prospectiva ${ }^{50}$. Por último, y estas es probablemente la parte menos obvia, puesto que lo anterior hace referencia solamente a las dimensiones formales de la norma de derecho, para comenzar a explicar cómo las medidas de justicia transicional pueden contribuir al fortalecimiento de la norma de derecho

48 Véase DE GREIFF, Pablo. Truth-Telling and the Rule of Law. En: BORER, Tristan A. (Ed.). Telling the Truths, Truth Telling and Peacebuilding in Post-Conflict Societies. Notre Dame, University of Notre Dame Press, 2006.

49 Véase DE GREIFF, Pablo. Vetting and Transitional Justice. En: MAYER-RIECKH, Alexander y DE GREIFF, Pablo (Eds.). Justice as Prevention. Vetting Public Employees in Transitional Societies. Nueva York, Social Sciences Research Council.

50 Véase DE GREIFF, Pablo. Truth-Telling and the Rule of Law. En: BORER, Tristan A. (Ed.). Telling the Truths, Truth Telling and Peacebuilding in Post-Conflict Societies. Notre Dame, University of Notre Dame Press, 2006, para un examen más detallado de las formas en las que el esclarecimiento de la verdad puede contribuir al fortalecimiento de la norma de derecho. 
democrática apelaría a uno de los dos mecanismos que mencioné anteriormente, su capacidad para articular y desarticular grupos sociales. Vale la pena comenzar recordando que parte del punto del ejercicio de ciertos tipos de terror es, precisamente, impedir la libre operación de la sociedad civil y de la esfera pública; uno de los usos del terror es aislar a los individuos y prevenir la consolidación de una oposición efectiva ${ }^{51}$. En contraste, se puede decir que la organización de la sociedad civil -junto con la desarticulación de grupos de violencia organizada, incluyendo los estatales- "empodera", entre otras razones, por el "poder de la agregación". Para enfrentar la violencia organizada y sistémica, por supuesto hace mucha diferencia si hay posibilidades de responder a ésta como parte de un grupo o si hace falta enfrentarla individualmente.

Pero esto es solo el comienzo. El punto claro está, no es uno de números, simplemente, sino de las actividades a las cuales los grupos relevantes para esta discusión se dedican: estos tienen en su núcleo la reclamación, esto es, no la súplica, sino la afirmación del reconocimiento de cierto estatus, de derechos. Esta es la razón fundamental por la cual los regímenes que se comprometen con la autonomía -lo que North, Wallis and Weingast Ilaman "órdenes de acceso abierto" - se comprometen a respetar normas asociativas "liberales", para no hablar de su compromiso con restricciones a la distribución y ejercicio del poder a través de leyes formales que regulan, entre otros, los procesos de transformación institucional ${ }^{52}$.

Antes de concluir esta breve discusión acerca de la adecuación funcional de las medidas de justicia transicional quiero hacer dos comentarios relacionados entre sí. Por supuesto, los "recuentos razonables" que intentan mostrar las cadenas causales que pueden conducir desde la implementación de las diferentes medidas al logro de cada uno de lo que he insistido que son sus tres objetivos característicos $^{53}$, coinciden en gran medida, se solapan: apelan a la afirmación de normas, uno de los dos mecanismos que mencioné anteriormente como cruciales para explicar el funcionamiento de las medidas de justicia transicional. Aparte de hacer explícita esta sobreposición, aprovecho, en segundo lugar, para hacer explícito también que los dos mecanismos no son igualmente fundamentales. La afirmación de normas, como mecanismo social, tiene prioridad -aun desde el punto de vista explicativo- sobre la articulación y desarticulación de grupos sociales, como queda claro por el hecho de que esta última capacidad tiene que referirse a normas si ha de servir los intereses de la justicia. Después de todo, es siempre posible articular grupos para servir causas injustas y desarticular grupos que defienden causas justas. Nuevamente, es necesaria una base normativa para establecer los parámetros (amplios) que deben aceptar los grupos admisibles (por ejemplo, las mafias no lo son), el tipo de reclamos que legítimamente pueden defender (la exterminación de otros grupos es usualmente ilegal), los medios que estos grupos pueden usar en la búsqueda de sus fines (aun si sus fines son legales, como queda de manifiesto en los intentos de prevenir la formación de monopolios), para mencionar sólo algunas de las restricciones más obvias que las normas imponen en la articulación y desarticulación de grupos.

51 Como lo dijo Arendt, "el gobierno totalitario, como todas las tiranías, ciertamente no podría existir sin destruir la esfera pública de la vida, esto es, sin destruir las capacidades políticas de los hombres, aislándolos unos de otros." ARENDT, Hannah. The Origins of Totalitarianism. New York, Harcourt, 1985 [trad. esp. ARENDT, Hannah. Los Orígenes del Totalitarismo. Madrid: Taurus, 1997, p. 475.

52 NORTH, Douglass, WALLIS, John J., WEINGAST, Barry. Violence and Social Orders: A Conceptual Framework for Understanding Recorded Human History. New York, Cambridge University Press, 2008.

53 Los cuales, por supuesto, merecen más elaboración de la que les puedo dar en este espacio. 


\section{Algunas observaciones acerca de cómo esta concepción normativa de la justicia transicional contribuye a enfrentar los retos pendientes}

A modo de conclusión, tan solo unas breves reflexiones acerca de la forma como este modelo de la justicia transicional puede contribuir a enfrentar los retos que el campo enfrenta. Estos retos los describí en términos de interrogantes acerca de la coherencia tanto interna como externa del campo; algunos tienen que ver con la forma como el campo ha de pensar acerca de las relaciones entre sus diferentes componentes. He resumido, grosso modo, claro está, un modelo teórico-normativo de la justicia transicional que está diseñado, en parte, para responder a este reto; y que explica la relación entre las diferentes medidas atribuyéndoles tres fines comunes, el reconocimiento, la confianza cívica y el fortalecimiento de la norma de derecho democrática. Dicho modelo muestra no sólo la relación entre esos fines, sino su relación con la justicia, y explica, lo cual es tan importante como inusual dado el estado presente de las ciencias sociales, cómo puede entenderse, desde el punto de vista de las relaciones causales y no solo de las correlaciones, la forma como la implementación de las normas puede ${ }^{54}$ conducir al logro de los fines ${ }^{55}$.

Aparte de esto, el modelo también puede ser útil en la resolución de los retos "externos" que el campo enfrenta, relacionados a la articulación de los vínculos posibles entre la justicia transicional y otros campos de intervención y a la forma como debe responderse a interrogantes acerca del "impacto" del trabajo en esta área; tengo aquí dos preocupaciones subyacentes. Una es que el campo está constituido por medidas ya sobrecargadas, que aun en circunstancias favorables encuentran difícil lograr sus fines limitados. Otra es que el contexto en el cual la justicia transicional se implementa hoy impone demandas aún más exigentes que aquellas que el campo encontró en sus orígenes. Pensar que el campo agota la agenda de las transformaciones en este nuevo contexto es en mi opinión cada vez más costoso, más ingenuo, y que descansa sobre la indiferencia a la reflexión seria acerca de lo que separa la retórica cada vez más reformista del campo y los instrumentos de los que efectivamente dispone. La solución para mí pasa por aclarar las formas en las que la justicia transicional puede entrelazarse con otros campos de intervención como la seguridad y el desarrollo (dos temas predominantes en la agenda internacional) y no en la asunción de que la justicia transicional, por sí sola, responde a estas necesidades ${ }^{56}$.

Puede resultar controvertido afirmar, como se desprende de mi argumento, que la justicia transicional es un intento por utilizar medidas judiciales y no judiciales para fortalecer regímenes de derechos formales. Esto establece ciertos límites al concepto de justicia transicional. Pero si ha de enfrentarse de forma seria el reto de cómo responder a las preguntas sobre el impacto del campo, y si ha de hacerse de manera que resulten explicables (causalmente) sus contribuciones, en vez de simplemente expresar aspiraciones, estos límites son finalmente útiles; permiten articular tanto el potencial como las razones por las cuales el campo necesita vínculos con otras políticas.

54 La modalidad es importante, para evitar malentendidos.

55 Por supuesto, creo que hay formas alternativas de concebir la justicia transicional. Pero cualquier concepción defendible pienso que debe aceptar las mismas cargas: (a) darle sentido a la práctica, (b) hacerlo de forma que mantenga suficiente peso normativo como para permitir la crítica, (c) ayudar a entender la relación entre sus diferentes componentes, (d) explicar cómo las diferentes medidas pueden lograr los fines que se les atribuyen, (e) contribuir a entender las relaciones entre el campo y otras tipos de intervención, y (f) ayudar a guiar el desarrollo futuro del campo. Este tipo de aproximación sistemática, que requiere la contribución de la teoría, no se ha intentado en el campo de la justicia, en general -y no solo en el de la justicia transicional-con frecuencia.

56 El objetivo que me trazo tanto en el trabajo que hice para el Banco Mundial en el curso del Reporte de Desarrollo Mundial 2011, Conflicto, Seguridad y Desarrollo "Transitional Justice, Security and Development", accesible en: http:// wdr2011.worldbank.org/sites/default/files/pdfs/WDR\%20Background\%20Paper_de\%20Greiff.pdf?keepThis=true\&TB_i frame $=$ true \&height $=600 \&$ width $=800$, como en DE GREIFF, Pablo. Articulating the Links between Transitional Justice and Development: Justice and Social Integration. En: DE GREIFF, Pablo y DUTHIE, Roger (Eds.). Transitional Justice and Development: Making Connections. New York, Social Science Research Council, 2009. 
La justicia transicional, entendida de esta manera tiene todo el potencial de las medidas del derecho formal. Es más convincente afirmar que un régimen robusto de derechos ciudadanos es importante para el desarrollo (argumento que puede hacerse desde el punto de vista instrumental, constitutivo -el desarrollo consiste por lo menos en parte en la institucionalización de estos derechos- o constructivista - los derechos ciudadanos son necesarios para definir el contenido y el alcance del desarrollo) y que la justicia transicional puede contribuir al establecimiento o al fortalecimiento de tales regímenes mediante los mecanismos mencionados. Esta perspectiva resulta más conveniente que insistir en que, por ejemplo, programas de reparaciones (con presupuestos usualmente nimios desde el punto de vista macroeconómico) tienen un impacto positivo en el desarrollo. La evaluación del impacto de la justicia transicional en uno u otro caso será bastante diferente. De la misma manera, la justicia transicional, entendida de la forma que defiendo aquí, tiene el potencial característico de los regímenes de derecho en la construcción de la paz. El derecho descansa sobre asunciones de cumplimiento más o menos generalizado. No fue primordialmente concebido como un instrumento para alcanzar la paz, sino para estabilizar relaciones sociales. Esto no quiere decir que no sea útil en procesos de paz. No hay paz sostenible a largo plazo que no redima reclamos de justicia. Pero, de nuevo, tener en mente los fines que las medidas fueron diseñadas para lograr hace una diferencia tanto en la evaluación de su impacto como en la urgencia con la cual se buscan vínculos con otro tipo de intervenciones.

Para establecer relaciones entre dos entidades, el reconocimiento de la identidad de cada una de ellas no es una limitación, sino una precondición. A los retos de la coherencia externa que el campo enfrenta hay una respuesta que no consiste en la proliferación de fines meramente "aspiracionales", sino en la reflexión metódica acerca de lo que los instrumentos de los que el campo dispone pueden lograr, y de cómo han de vincularse con otros tipos de intervenciones que también hacen parte de procesos complejos de transformación política, económica y social. La teoría ayuda en la tarea de dilucidar tanto potenciales como necesidades. 